\title{
Feeding microalgae at a high level to finishing heifers increases the long-chain n-3 fatty acid composition of beef with only small effects on the sensory quality
}

by Rodriguez-Herrera, M., Khatri, Y., Marsh, S. P., Posri, W. and Sinclair, L. A.

Copyright, Publisher and Additional Information: This is the author accepted manuscript. The final published version (version of record) is available online via Wiley. This article may be used for non-commercial purposes in accordance with Wiley Terms and Conditions for Self-Archiving.

Please refer to any applicable terms of use of the publisher.

DOI: https://doi.org/10.1111/ijfs.13718

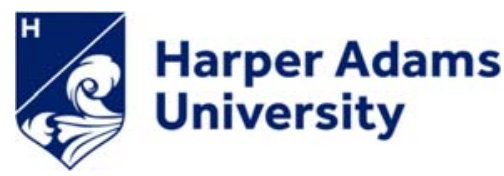

Rodriguez-Herrera, M., Khatri, Y., Marsh, S. P., Posri, W. and Sinclair, L. A. 2017. Feeding microalgae at a high level to finishing heifers increases the long-chain $n-3$ fatty acid composition of beef with only small effects on the sensory quality. International Journal of Food and Science Technology. 


\section{Feeding microalgae at a high level to finishing heifers increases the long chain n-3 fatty acid composition of beef with only small effects on the sensory quality.}

Maricruz Rodriguez-Herrera ${ }^{1}$, Yunus Khatri ${ }^{1}$, Simon P. Marsh ${ }^{2}$, Wilatsana Posri ${ }^{1}$ \& Liam A. Sinclair ${ }^{2}$

${ }^{1}$ Department of Food Science and Agri-Food Supply Chain Management, Harper Adams University, Edgmond, Newport, Shropshire TF10 8NB, UK.

${ }^{2}$ Department of Animal Production, Welfare and Veterinary Sciences, Harper Adams University, Edgmond, Newport, Shropshire TF10 8NB, UK.

Corresponding author: Isinclair@harper-adams.ac.uk

Running head: Microalgae and beef quality 
Summary The aim of the study was to determine the effect of feeding a low and high level of microalgae (MA, high in $\mathrm{C} 22: 6 n-3)$ on the fatty acids (FA) composition and sensory attributes of beef. Thirty Charolais cross Limousin/Friesian heifers were fed one of three diets ( $n=10$ per treatment): Control (no MA), low MA (LMA; inclusion rate of 15 $\mathrm{g} / \mathrm{kg}$ ) or high MA (HMA; inclusion rate of $30 \mathrm{~g} / \mathrm{kg}$ ) for 95 days before slaughter. Heifers fed HMA had a higher $(P<0.05)$ content of C20:5n-3: eicosapentaenoic acid (EPA), and C22:6n-3: docosahexaenoic acid (DHA) in the longissimus thoracis muscle than those receiving the Control (mean values for EPA of 0.5, 0.92, 1.20 and DHA of 0.31, 0.89 and $1.05 \mathrm{~g} / 100 \mathrm{~g}$ FA for Control, LMA and HMA respectively), and a lower n-3 to $\mathrm{n}$ 6 ratio $(2.9,1.9$ and 1.6 in Control, LMA and HMA respectively; $P<0.001)$. Steaks from animals fed either of the MA diets had a marginally higher $(P<0.05)$ "seaweedy flavour" that was positively correlated to muscle $\mathrm{C} 22: 6 n-3$ concentration. Steaks from animals fed HMA were rated as being higher $(P<0.05)$ in tenderness, and had a lower $(P<0.05)$ shear force than those from Control fed animals. It is concluded that feeding microalgae at high levels can beneficially improve the health attributes of beef with only a few effects on sensory quality.

Keywords: Beef, fatty acid, muscle tissue, sensory evaluation. 


\section{Introduction}

The very long chain n-3 polyunsaturated fatty acids (LC n-3 PUFA) eicosapentaenoic acid (EPA; C20:5n-3) and docosahexaenoic acid (DHA; C22:6n-3) have been shown to have benefits in the modulation and prevention of coronary heart disease, in the early development and maintenance of retinal and brain tissues, and in the prevention of certain cancers (Abedi \& Sahari, 2014; Zárate et al., 2017). Oil-rich fish and fish oil have traditionally been the main sources of LC n-3 PUFA in the human diet (Welch et al., 2002). However, the consumption of fish varies regionally, and in many western countries such as the UK are in decline (Welch et al., 2002). The current intake of EPA

+ DHA in the UK is approximately $100 \mathrm{mg} /$ day, which is considerably lower than the recommended value of $250-450 \mathrm{mg} /$ day (SACN \& COT, 2004; EFSA, 2010). Alternative dietary sources of these fatty acids (FA) such as meat based foods is therefore of considerable interest.

Beef has long been recognized as a valuable source of EPA and DHA in the human diet (Wood et al., 2008). It has been proposed that the levels of LC n-3 PUFA in beef can be increased further by feeding dietary sources rich in those FA (Gibbs et al., 2010). Feeding microalgae (MA) has been proposed as a means to improve the EPA and DHA content of beef, mainly because it is a rich source of LC n-3 PUFA (Givens et al., 2006; Zárate et al., 2016), and the degree of ruminal biohydrogenation has been reported to be lower than in other sources such as fish oil (Sinclair et al., 2005). Previous studies have reported an increase in muscle deposition of LC n-3 PUFA following feeding of MA to lambs (Cooper et al., 2004; Hopkins et al., 2014; Meale et al., 2014). However, few studies have evaluated the effect of feeding MA to cattle, particularly at high rates of inclusion, in concentrate finishing systems or when slaughtered at a low body fat content (Phelps et al., 2016a,b).

Modifying the FA composition of muscle may influence certain characteristics of meat quality, including flavour, texture and lipid stability (Wood et al., 2008). Highly 
unsaturated FA such as LC n-3 PUFA are more susceptible to oxidation during retail and cooking, and high concentrations of these FA in the muscle can contribute to the development of undesirable off-flavours in cooked meat (Nute et al., 2007). Lipid oxidation is recognised as one of the main causes of the deterioration of meat quality, therefore one of the main challenges to studies attempting to increase the concentration of LC n-3 PUFA in meat is to avoid oxidation and maintain the eating quality. However, few studies have been conducted to determine the effect of the dietary inclusion of MA on the sensory attributes of beef and the relationship with meat FA content, particularly when fed at high levels. The objectives of this study were to determine the effects of a low and high inclusion rate of MA (rich in DHA) in the diet of finishing heifers on the FA composition of intramuscular fat and subcutaneous adipose tissue, and the sensory attributes of beef.

\section{Materials and method}

Diets, animals and experimental procedure

Thirty Charolais cross Limousin/Friesian heifers with an initial mean age of $24 \pm 0.8$ months and live weight of $509 \pm 40.0 \mathrm{~kg}$ were used. Prior to the study the animals were fed medium quality grass silage and were gradually adapted to a cereal based diet over a period of $17-d$. After this period the animals were blocked according to live weight and randomly allocated within block to one of the three experimental diets, resulting in ten animals per diet. Three rates of MA (Schizochytrium limacinum; Alltech UK Ltd., Lincs, UK) were fed; Control (no MA), low MA (LMA; $15 \mathrm{~g} / \mathrm{kg}$ dietary inclusion of MA) and high MA (HMA; $30 \mathrm{~g} / \mathrm{kg}$ dietary inclusion of MA). The Control diet contained (g/kg) 750 barley, 100 dried, molassed sugar beet pulp, 75 soyabean meal, 50 molasses and 25 minerals and vitamins, with the proportional replacement of barley with MA in diets LMA and HMA. The MA was in the form of a dried powder with a lipid content of $580 \mathrm{~g} / \mathrm{kg}$ dry matter (DM), and contained an EPA and DHA content of 0.28 and $27.2 \mathrm{~g} / 100 \mathrm{~g}$ FA respectively. 
The diets were formulated to have a similar energy content and to be isonitrogenous, with vitamin $\mathrm{E}$ added as an antioxidant at $250 \mathrm{mg} / \mathrm{kg}$.

Treatment diets were offered ad libitum via hoppers for 95 days with free access to wheat straw. Animals were double weighed at the beginning and end of the study using electronic weigh cells (Tru-Test, Auckland, New Zealand). Following slaughter in a commercial abattoir (ABP, Shrewsbury, UK) using a captive bolt and severing the arteries, the carcasses were hung for $48 \mathrm{~h}$ at $4^{\circ} \mathrm{C}$, weighed and scored for conformation and fat class using a 15-point scale based on RPA (2011), where $1=$ lowest and $15=$ highest. Samples from the longissimus thoracis muscle and the subcutaneous adipose tissue (at the 10-12th rib) were then dissected vacuum-packaged and stored at $-20^{\circ} \mathrm{C}$ prior to $\mathrm{FA}$ analysis, or conditioned at $1^{\circ} \mathrm{C}$ for $10 \mathrm{~d}$ and then stored at $-20^{\circ} \mathrm{C}$ prior to sensory analysis, as described by Vatansever et al. (2000) and Nute et al. (2007).

Fatty acid analysis

The FA content of muscle and subcutaneous adipose tissue of all animals $(n=10$ per treatment) was conducted according to the method described by O'Fallon et al. (2007) using C13:0 as an internal standard. Following methylation the FA's were analysed on a gas chromatograph (HP 6890, Germany) equipped with an auto sampler (Agilent 6890 injector, UK), a split injector and a flame-ionization detector (Agilent Inc. Wilmington, DE). The separations were performed on a CP-SIL 88 for FAME capillary column, $100 \mathrm{~m}$ length $\times 0.25 \mathrm{~mm}$ internal diameter and $0.2 \mu \mathrm{m}$ film thickness (Agilent J\&W, GC columns, UK). Oven temperature was first held at $70^{\circ} \mathrm{C}$ for $2 \mathrm{~min}$, then increased by $8{ }^{\circ} \mathrm{C} / \mathrm{min}$ to $100{ }^{\circ} \mathrm{C} ; 5{ }^{\circ} \mathrm{C} / \mathrm{min}$ to $170{ }^{\circ} \mathrm{C}$ and finally $4{ }^{\circ} \mathrm{C} / \mathrm{min}$ to $225^{\circ} \mathrm{C}$; this temperature was maintained until all peaks were analysed. The split ratio was 100:1. Hydrogen was used as the carrier gas and peaks were identified by comparison of retention times with a standard mixture (Supelco ${ }^{\circledR} 37$ Component FAME Mix, Sigma-Aldrich, Dorset, UK). The area for each FA was adjusted using the recovery factors from a standard Supelco ${ }^{\circledR} 37$ 
mixture, and normalized to $100 \%$. Total FA content was quantified by reference to the area of the internal standard. The fatty acids were expressed as $\%$ of total fatty acids in intramuscular fat and subcutaneous adipose tissue, or mg/100 $\mathrm{g}$ fresh tissue (Cooper et al., 2004; Nute et al., 2007; Wachira et al., 2004). Feed samples were bulked within month (resulting in $n=3$ per treatment) and their FA composition determined by the method of Jenkins (2010; Table S1). Feed samples were also analysed according to AOAC (2012) for DM (method 934.01), ash (942.05), crude protein (CP; 990.03 using a Leco® FP-528 analyzer, LECO Corporation, USA), and neutral detergent fibre (NDF; Van Soest et al., 1991).

Sensory assessment and shear force

The steaks were thawed overnight at $4{ }^{\circ} \mathrm{C}$ and then cooked using an auto-controlled roasting/baking oven (Self-Cooking Center ${ }^{\circledR}$ SCC 101, Rational AG, Germany). The samples were cooked, turning over half way through, and the internal temperature verified with a thermocouple probe (Therma 20, ETL Ltd, UK) inserted into the centre of each steak to ensure that it reached at least $73^{\circ} \mathrm{C}$.

A descriptive sensory analysis was performed by 10 trained panellists. Following recruitment, the assessors were screened on the basis of their sensitivity to five basic tastes, ability to detect specific odours, numerical competence with respect to scaling and descriptive ability (BSI, 2014). The panellists were trained and calibrated for beef profiling in accordance with the guidelines of BS EN ISO 8586:2014 (BSI, 2014) and Gomes et al. (2014). During the training stage the panellists followed seven training sessions of two hours each with an open discussion to generate the lexicon to describe the beef steaks in terms of odour, taste, texture and after taste. The standard references for key sensory attributes were provided (adapted from Adhikari et al., 2011, and Maughan et al., 2012). There were also ballot training sessions conducted on the consensus lexicon, rating scale used (unstructured $15 \mathrm{~cm}$ line scale with two anchor 
words) and intensity calibration using standard references with an interactive feedback screen using Compusense ${ }^{\circledR}$ five (Compusense., Guelph, Ontario, Canada). The performances of individual panellists and the panel were tested for their reliability and validity in order to retain, adjust and calibrate the measurements. The sensory profiles of all treatments (3) and replicates of treatments (10) were evaluated on the consensus ballot based on 2 test replications, resulting in the profiling of 60 meat samples. The sensory evaluation took place over 5 consecutive days, with the first three sessions allocated for the first test replication and the last three for the second. A Williams crossover design was applied within each test replication to randomly balance first-order and carry-over effects. The evaluation sessions took place in individual booths equipped with Compusense computerised software. Five $1.5 \mathrm{~cm}$ steak cubes of each sample were served at room temperature and presented in a random order.

Shear force of the cooked steaks was measured based on the method described by Peachey et al. (2002), using a TA.HD Plus Texture Analyzer (Stable Micro Systems Ltd., Surrey, UK), fitted with a Warner Bratzler blade with a rectangular slot and $30 \mathrm{~kg}$ load cell. Five $10 \mathrm{~mm}$ cubes from each sample were assessed. The cubes were sheared perpendicular to the fibre orientation with $2.0 \mathrm{~mm} / \mathrm{s}$ crosshead speed. The resistance of the meat to shearing was recorded every $0.005 \mathrm{~s}$ and a curve (time vs. force) plotted. The parameters recorded were "Maximum shear force" $(\mathrm{N})$, indicating the maximum force required to cut through the sample and "Work of shear" (N.s), which relates to the total work done to cut the sample, also referred as "toughness".

Statistical analysis

The FA content of tissues, sensory analysis, texture of cooked steaks and animal performance were analyzed using ANOVA as a randomized complete block design. The statistical model was $y i j=b i+t j+e i j$, where $b=$ blocks and $t=$ treatments. Daily live weight gain was calculated as the final weight minus the initial weight divided by the 
number of days on study. The results are presented as means for the treatments with s.e.d., and post-hoc analysis using Tukey's test at a 5\% significance level. Pearson correlation coefficients were generated to describe the association between sensory scores and the percentage of n-3 PUFA in muscle, along with linear regression to obtain the significance values for the model. All analysis was conducted using Genstat $\left(16^{\text {th }}\right.$ edition; VSN International Ltd., Oxford, UK).

\section{Results and discussion}

Fatty acid content of the longissimus thoracis muscle

The proportion of C22:6n-3 in the longissimus thoracis muscle was highest $(P<$ 0.05) in cattle receiving the HMA diet and lowest in those receiving the Control diet, with those receiving LMA being intermediate (Table 1), with values comparable to other studies that have fed MA to sheep or cattle (Hopkins et al., 2004; Phelps et al., 2016a). The muscle from heifers fed the HMA diet also had the highest $(P<0.05)$ proportion of C20:5n-3, followed by LMA, with those receiving the Control diet the lowest. By contrast, the proportion of $\mathrm{C} 22: 5 \mathrm{n}-3$ decreased $(P<0.05)$ with the inclusion of MA in the diet. The highest $(P<0.05)$ proportion of eicosatrienoic $(C 20: 3 n-6)$ and docosatetraenoic acid $(\mathrm{C} 22: 4 n-6)$ was observed in the longissimus thoracis muscle from animals fed the Control diet, while that from animals fed the HMA diet contained the lowest $(P<0.05)$ proportion. Other authors have also reported that the dietary inclusion of LC n-3 PUFA is an effective means to increase their content in muscle in ruminants. In a similar study in finishing lambs, Cooper et al. (2004) reported an increase in the proportion of EPA and DHA in muscle when fish oil and MA were included in the diet, but the proportions of EPA and DHA were considerably higher than those obtained in the current study, reflecting the different dietary inclusion level in both studies. The increase in muscle content of EPA in the current study was achieved despite negligible amounts of this FA being present in the MA. This finding is similar to that reported by others (Phelps et al., 
2016a, Díaz et al., 2017) and may be explained by the retro-conversion of DHA to EPA as suggested by Cooper et al. (2004). Alternatively, the activity of the FADS1 gene which encodes the $\Delta 5$ desaturase enzyme responsible for the conversion of $20: 4 n-3$ to $20: 5 n$ 3 has been shown to be upregulated in liver and muscle following supplementation with MA in lambs, although the response in muscle is less predictable (Alvarenga et al., 2016).

Phelps et al. (2016a) fed 50, 100 or $150 \mathrm{~g}$ per day of MA to finishing heifers and reported a quadratic response in muscle EPA and DHA concentration, reaching a maximum of $19 \mathrm{mg} / 100 \mathrm{~g}$ tissue. In the current study the two dietary treatments of MA equated to feeding approximately 150 and $300 \mathrm{~g} \mathrm{MA} /$ animal $/ \mathrm{d}$, with muscle $\mathrm{DHA}$ concentration increasing with MA inclusion level to $33 \mathrm{mg} / 100 \mathrm{~g}$ tissue in animals fed HMA. Differences between the current study and Phelps et al. (2016a) may partly be explained by the basal diet, with high levels of barley being fed in the current study. High levels of starch rich ingredients such as barley is associated with a lower ruminal $\mathrm{pH}$ and a reduction in the biohydrogenation of PUFA in the rumen (Sinclair et al., 2007). This may have increased the duodenal flow and subsequent muscle supply of EPA and DHA. Despite the absence of LC n-3 PUFA in the Control diet, the meat from cattle fed this diet was found to contain small amounts of EPA and DHA. These FA would have been synthesised by the animal via elongation and desaturation of its precursor $C 18: 3 n-3$, but as discussed by Sinclair (2007), this process is relatively inefficient in ruminants compared to the dietary supply and muscle uptake of pre-formed LC n-3 PUFA.

The decrease in the proportion of $\mathrm{C} 20: 3 n-6$ and $C 22: 4 n-6$ in the muscle from cattle fed either of the MA diets in the current study is consistent with previous studies, which also reported a decline in the proportion of n-6 PUFA when dietary sources of LC n-3 PUFA were fed to beef cattle (Dunne et al., 2011; Phelps et al., 2016a,b). In the current study, the FA composition of the intramuscular fat was analysed without separating polar and neutral lipids. However, the increase in the proportions of EPA and DHA in muscle from animals fed MA can most likely be attributed to changes in the 
composition of the phospholipid $(\mathrm{PL})$ fraction, as several studies have reported that the largest deposition of LC n-3 PUFA occurs in the PL fraction of the intramuscular fat. The content of $\mathrm{PL}$ in muscle is relatively constant and therefore any increase in the deposition of LC n-3 PUFA is probably due to the substitution for other similar FA, mainly the $n-6$ PUFA (Sinclair 2007; Wood et al., 2008).

Muscle content of C18:3n-3 averaged $0.14 \mathrm{~g} / 100 \mathrm{~g} \mathrm{FA}$ and was not affected $(P>$ 0.05 ) by treatment, reflecting the similarity in content of this FA across all three diets. Despite the replacement of LC n-6 PUFA in muscle with the inclusion of MA, there was no effect of diet $(P>0.05)$ on the proportion of $C 18: 2 n-6$ or arachidonic acid $(20: 4 n-6)$. The highest $(P<0.05)$ proportion of $\mathrm{C} 16: 0$ and $\mathrm{C} 18: 0$ was observed in muscle from cattle fed HMA, and reflects the greater dietary concentration. In contrast, dietary C18:1n-9 concentration was similar between the three treatments but its content was lower $(P<$ 0.05) in muscle from cattle fed either of the MA diets. Wachira et al. (2002) reported that muscle concentrations of $\mathrm{C} 18: 1 \mathrm{n}-9$ can be reduced due to the substitution by other unsaturated FA in the PL fraction of the intramuscular fat. Similarly Cooper et al. (2004) found that C18:1n-9 was replaced by EPA and DHA in the muscle lipid of lambs when fed LC n-3 PUFA, although Phelps et al. (2016a) found no effect of the inclusion of MA in the diet on muscle C18:1n-9.

Intramuscular fat indices and human health:

In the European Union the reference intake values of EPA plus DHA for humans is 250 $\mathrm{mg} /$ day (EFSA, 2010). A $100 \mathrm{~g}$ serving of beef meat from the animals receiving the LMA treatment would supply approximately $62.2 \mathrm{mg}$ of these LC $\mathrm{n}-3$ PUFA, while a $100 \mathrm{~g}$ serving of meat from the HMA fed animals would supply approximately $71.2 \mathrm{mg}$. These values represent a supply of approximately 25 to $28 \%$ of the recommended daily requirement. A food product can be marketed within Europe as being a "source of omega-3 fatty acids" when it contains at least $40 \mathrm{mg} / 100 \mathrm{~g}$ of EPA plus DHA, and as 
being "high in omega-3 fatty acids" when it contains at least $80 \mathrm{mg} / 100 \mathrm{~g}$ (Commission Regulation of the European Union, 2010). Meat from animals fed the Control treatment contained $25.4 \mathrm{mg}$ of EPA plus $\mathrm{DHA} / 100 \mathrm{~g}$, and therefore does not meet the minimum content. In contrast, meat from cattle fed either of the diets containing MA meet the required levels of EPA plus DHA to be labelled as a food product that is a "source of omega-3 fatty acids", but not to be "high in omega-3" fatty acids.

There was no effect $(P>0.05)$ of dietary treatment on the content of SFA, MUFA or PUFA in the longissimus thoracis muscle (Table 2). Similarly, the dietary inclusion of MA did not alter $(P>0.05)$ the polyunsaturated to saturated $(P: S)$ ratio of muscle, with a value of approximately 0.2 for all treatments. This ratio is similar to that reported by Hopkins et al. (2014) and Phelps et al. (2016a), but lower than that of Cooper et al. (2004), who reported a P:S ratio of 0.46 in muscle from lambs when fed rumen protected linseed and MA. However, the dietary addition of MA in the current study did lead to a large improvement $(P<0.05)$ in the n-6:n-3 ratio, being 2.9, 1.9 and 1.6 in the muscle from animals fed the Control, LMA or HMA diet respectively. A recommended value for the $n-6: n-3$ ratio in the human diet is approximately 2 , and therefore the meat from cattle fed either diet containing MA comply with this, while those fed the Control diet in the current study, or cattle fed similar concentrate based diets (Dunne et al., 2011; Phelps et al., 2016a), do not. This improvement in the n-6:n-3 ratio is consistent with other studies where sources of LC n-3 PUFA have been included in the diet of ruminants (e.g. Wachira et al., 2002; Phelps et al., 2016a).

Fatty acid content of the subcutaneous adipose tissue

The FA content of the subcutaneous adipose tissue was analysed in the current study as some consumers, when given the choice, may choose to consume the fat on a portion of meat, whilst others may prefer to cook in tallow rather than vegetable oil. The total FA content in the subcutaneous adipose tissue was similar in animals receiving any 
of the three diets, with an average value of $79753 \mathrm{mg} / 100 \mathrm{~g}$ of tissue $(P>0.05$; Table 3). The subcutaneous adipose tissue from heifers fed the Control diet had the highest $(P$ $<0.05$ ) content of C18:2n-6, C20:3n-6 and total n-6 FA, while those fed the HMA diet had the lowest. In contrast, the content of C22:5n-3 was highest $(P<0.05)$ in the subcutaneous adipose tissue from animals fed the LMA or HMA diet, and lowest in those fed the Control diet. The highest $(P<0.05)$ content of C14:0, C16:0 and C18:1 trans-9 was observed in the subcutaneous adipose tissue from cattle fed the HMA diet, whereas the levels of $\mathrm{C} 18: 1$ trans-11, C18:1n-9 and C18:2 cis-9, trans-11 were highest $(P<0.05)$ in animals fed the Control diet. The minor effect of the inclusion of MA in the diet on the proportion of EPA and DHA in the subcutaneous adipose tissue in the current study reflects the low incorporation of these FA in the triacylglycerol fraction and the low proportion of PL found in the adipose tissue (Cooper et al., 2004). Contrary to this, Meale et al. (2014) reported a large increase of LC n-3 PUFA in subcutaneous adipose tissue and perirenal adipose tissue of lambs when MA was fed.

Sensory quality and shear force

Steaks from cattle fed HMA were scored as having the highest $(P<0.05)$ intensity of the attribute "seaweedy flavour", followed by the steaks from cattle fed the LMA diet and the Control animals the lowest (Table 4 and Figure 1). The attribute "seaweedy flavour" was defined by the sensory panel as "the mixture of grassy, seaweedy and/or fishy flavours". This finding is consistent, although less pronounced than that reported by Vatansever et al. (2000), where steaks from cattle fed fish oil were described as containing a higher "fishy flavour" than those from animals fed a control diet. Similarly, Phelps et al. (2016a,b) reported an increase in off-flavour intensity in beef from animals fed higher levels of MA, whilst Nute et al. (2007) reported that meat from lambs fed dietary sources of LC n-3 PUFA had higher scores for a number of attributes including "fishy flavour", "rancid flavour" and "abnormal lamb flavour". Vatansever et al. (2000) also reported a decrease 
in "beef flavour" and increase in "livery flavour" in steaks from cattle fed fish oil, although no differences were detected in the current study. There was also no effect $(P>0.05)$ of dietary treatment in the current study on any of the other sensory attributes, except for "tenderness", with meat from animals fed the HMA diet having the highest score (i.e. most tender), while those from animals fed LMA had the lowest score $(P<0.001)$. Similar to the sensory evaluation, steaks from animals fed LMA had the highest $(P<0.05)$ shear force and toughness, while those from cattle fed the HMA diet had the lowest. Other authors have found little effect of LC n-3 PUFA content on toughness (Nute et al., 2007; Phelps et al., 2016a) and reasons for the differences in the current study are unclear.

There was a positive correlation $(P<0.05)$ between the proportion of EPA and DHA in the intramuscular fat and "seaweedy flavour" scores in steaks, with DHA having the strongest positive correlation coefficient of 0.6 followed by EPA at 0.48 (Supplementary Table S2). This is the first study to report this finding in cattle fed MA, but is consistent with the results of Nute et al. (2007) who reported a positive correlation between the "fishy flavour" in lamb meat and the proportion of EPA and DHA in the intramuscular fat. The volatile compounds formed in cooked meat are mainly derived from thermal degradation of lipids and the Maillard reaction (Calkins \& Hodgen, 2007). Thermal oxidation of lipids produces volatile compounds such as aliphatic aldehydes, ketones, and alcohols, which contribute to the flavour of meat (Mottram, 1994). Elmore et al. (1999), reported that cooked beef meat with high amounts of LC n-3 PUFA produced higher concentrations of lipid oxidation products, an effect that was also demonstrated in cooked lamb meat (Elmore et al., 2005). Elmore et al. (1999) also discussed that high contents of LC n-3 PUFA in meat could catalyse the degradation of other FA. Therefore, due to the low oxidative stability of LC n-3 PUFA, modifying its concentration in meat would result in alterations to the composition of the aroma volatiles produced during cooking, with lipid oxidation being related to the generation of off-odours and off-flavours such as "fishy", "greasy", "rancid" and "abnormal" (Wood et al., 2008). However, none of these attributes were detected in the current study. 
Few studies have documented the impact of MA on carcase quality or performance of beef animals. The lack of an effect of treatment in the current study (Table 5) is in agreement with studies that have fed MA to lambs (Cooper et al., 2004; Hopkins et al., 2014) or fish oil to cattle (Scollan et al., 2001). In contrast, Díaz et al. (2017) reported a decrease in daily weight gain in growing lambs when MA was included at $2 \%$ of the diet. Additionally, Stokes et al. (2015) reported a linear decrease in whole tract dry matter digestibility when partially deoiled MA was fed to lambs. Demirel et al. (2004) also reported an increase in carcase fat score when fish oil plus linseed was fed to sheep, which was attributed to an increase in the total FA content of the neutral lipid fraction of the muscle fat. Feeding levels of MA above those used in the current study should therefore take into account the potential decrease in diet digestibility and increase in carcase fat content.

\section{Conclusions}

The present study demonstrated that feeding microalgae is an effective means to increase the content of LC n-3 PUFA in beef meat, particularly the nutritionally beneficial EPA and DHA. The increase in EPA and DHA in meat was proportional to the inclusion rate of microalgae in the diet, and could permit the meat to be labelled as a source of omega-3 fatty acids, providing consumers with the choice of a meat containing healthier characteristics. However, the inclusion of microalgae was associated with the development of some undesirable flavours in meat. Future research should focus on evaluating different inclusion rates of microalgae in the diet in combination with additional antioxidants on lipid oxidation and sensory attributes.

\section{Acknowledgements}

The authors would like to acknowledge the technical assistance of G.Vince, Harper Adams University, for the animal care, and to Alltech UK Ltd., for funding the study. 


\section{References}

Abedi, E. \& Sahari, M.A. (2014). Long-chain polyunsaturated fatty acid sources and evaluation of their nutritional and functional properties. Food Science and Nutrition, 2, 443-463.

Adhikari, K., Chambers, E., Miller, R., Vázquez-Araújo, L., Bhumiratana, N. \& Philip, C. (2011). Development of a lexicon for beef flavour in intact muscle. Journal of Sensory Studies, 26, 413-420.

Alvarenga, T.I.R.C., Chen, Y., Lewandowski, P., Ponnamplan, E.N., Sadiq, S., Clayton, E.H., van de Ven, R.J., Perez, J.R.O. \& Hopkins, D.L. (2016). The expression of genes encoding enzymes regulating fat metabolism is affected by maternal nutrition when lambs are fed algae high in omega-3. Livestock Science 187, 53-60.

AOAC. (2012). Official methods of analysis. 19th ed. AOAC. Arlington, USA.

BSI. (2014). BS EN ISO 8586:2014. Sensory analysis: general guidelines for the selection, training and monitoring of selected assessors and expert sensory assessors. ISO. Switzerland.

Calkins, C.R. \& Hodgen, J.M. (2007). A fresh look at meat flavor. Meat Science, 77, 6380.

Campo, M.M., Nute, G.R., Hughes, S.I., Enser, M., Wood, J.D. \& Richardson, R.I. (2006). Flavour perception of oxidation in beef. Meat Science, 72, 303-311.

Commission Regulation of European Union (2010) Amending Regulation (EC) No 1924/2006 of the European Parliament and of the Council with regard to the list of nutrition claims. Official Journal of the European Union (No 116, February 2010).

Cooper, S.L., Sinclair, L.A., Wilkinson, R.G., Hallett, K.G., Enser, M. \& Wood, J.D. (2004). Manipulation of the n-3 polyunsaturated fatty acid content of muscle and adipose tissue in lambs. Journal of Animal Science, 82,1461-1470. 
Díaz, M.T., Pérez, C., Sánchez, C.I., Lauzurica, S., Cañeque, V., González, C. \& De La Fuente, J. (2017). Feeding microalgae increases omega 3 fatty acids of fat deposits and muscles in light lambs. Journal of Food Composition and Analysis, 56, 115-123.

Dunne, P.G., Rogalski, J., Childs, S., Monahan, F.J., Kenny, D.A. \& Moloney, A.P. (2011). Long chain n-3 polyunsaturated fatty acid concentration and color and lipid stability of muscle from heifers offered a ruminally protected fish oil supplement. Journal of Agricultural Food Chemistry, 59, 5015-5025.

EFSA Panel on Dietetic Products Nutrition and Allergies (NDA) (2010). Scientific opinion on dietary reference values for fats, including saturated fatty acids, polyunsaturated fatty acids, monounsaturated fatty acids, trans fatty acids, and cholesterol. European Food Safety Authority Journal, 8, 1461.

Elmore, J.S., Cooper, S.L., Enser, M., Mottram, D.S., Sinclair, L.A., Wilkinson, R.G. \& Wood, J.D. (2005). Dietary manipulation of fatty acid composition in lamb meat and its effect on the volatile aroma compounds of grilled lamb. Meat Science, 69, 233242.

Elmore, J.S., Mottram, D.S., Enser, M. \& Wood, J.D. (1999). Effect of the polyunsaturated fatty acid composition of beef muscle on the profile of aroma volatiles. Journal of Agricultural Food Chemistry, 47, 1619:1625.

Gibbs, R.A., Rymer, C. \& Givens, D.I. (2010). Long-chain n-3 PUFA: intakes in the UK and the potential of a chicken meat prototype to increase them. Proceedings of the Nutrition Society, 69, 144-155.

Givens, D.I., Kliem, K.E. \& Gibbs, R.A. (2006). The role of meat as a source of n-3 polyunsaturated fatty acids in the human diet. Meat Science, 74, 209-218.

Gomes, C.L., Pflanzer, S.B., Cruz, A.G., Felício, P.E. \& Bolini, H.M.A. (2014). Sensory descriptive profiling and consumer preferences of beef strip loin steaks. Food Research International, 59, 76-84.

Hopkins, D.L., Clayton, E.H., Lamb, T.A., Van de Ven, R.J., Refshauge, G., Kerr M,J., Bailes, K., Lewandowski, P. \& Ponnampalam, E.N. (2014). The impact of 
supplementing lambs with algae on growth, meat traits and oxidative status. Meat Science, $98,135-141$.

Jenkins, T.C. (2010). Technical note: common analytical errors yielding inaccurate results during analysis of fatty acids in feed and digesta samples. Journal of Dairy Science, 93, 1170-1174.

Maughan, C., Tansawat, R., Cornforth, D., Ward, R. \& Martini, S, (2012), Development of a beef flavor lexicon and its application to compare the flavor profile and consumer acceptance of rib steaks from grass- or grain-fed cattle. Meat Science, 90, 116-121.

Meale, S.J., Chaves, A.V., He, M.L. \& McAllister, T.A. (2014). Dose-response of supplementing marine algae (Schizochytrium sp.) on production performance, fatty acid profiles and wool parameters of growing lambs. Journal of Animal Science, 92, 2202-2213.

Mottram, D.S. (1994). Some aspects of the chemistry of meat flavour. In: The Flavour of Meat and Meat Products (edited by Shahidi, F.). Pp 210-230. Glasgow, UK: Chapman \& Hall.

Nute, G.R., Richardson, R.I., Wood, J.D., Hughes, S.I., Wilkinson. R.G., Cooper, S.L. \& Sinclair, L.A. (2007). Effect of dietary oil source on the flavour and the colour and lipid stability of lamb meat. Meat Science, 77, 547-555.

O’Fallon, J.V., Busboom, J.R., Nelson, M.L. \& Gaskins, C.T. (2007). A direct method for fatty acid methyl ester synthesis: Application to wet meat tissues, oils, and feedstuffs. Journal of Animal Science, 85, 1511-1521.

Phelps, K.J., Drouillard, J.S., O’Quinn. T.G., Burnett. D.D., Blackmon. T.L., Axman. J.E., Van Bibber-Krueger. C.L. \& Gonzalez, J.M. (2016a). Feeding microalgae meal (All-G Rich $^{\mathrm{TM}}$; Schzcochytrium limacinum CCAP 4087/2) to beef heifers I: Effects on longissimus lumborumn steak color and palatability. Journal of Animal Science, 94, 4016-4029.

Phelps, K.J., Drouillard, J.S., O’Quinn. T.G., Burnett. D.D., Blackmon. T.L., Axman. J.E., Van Bibber-Krueger. C.L. \& Gonzalez, J.M. (2016b). Feeding microalgae meal (All-G 
Rich $^{\text {TM; }}$ Schzcochytrium limacinum CCAP 4087/2) to beef heifers II: Effects on ground beef color and palatability. Journal of Animal Science, 94, 4030-4039.

Peachey, B.M., Purchas, R.W. \& Duizer, L.M. (2002). Relationships between sensory and objectives measures of meat tenderness on $\mathrm{m}$. longissimum thoracis from bulls and steers. Meat Science, 60, 211-218.

Rural Payments Agency (2011). Beef carcase classification scheme. Guidance on dressing specifications and carcase classification. Version 4. rpa.defra.gov.uk

Scientific Advisory Committee on Nutrition (SACN) and the Committee on Toxicity (COT) on the consumption of fish. (2004). Advice on fish consumption: benefits \& risks 2004 . Advice on Fish Consumption: Benefits \& Risks. Her Majesty's Stationery Office, Norwich, UK.

Scollan, N.D, Choi, N.J., Kurt, E., Fisher, A.V., Enser, M. \& Wood, J.D. (2001). Manipulating the fatty acid composition of muscle and adipose tissue in beef cattle. British Journal of Nutrition, 85, 115-124.

Sinclair, L.A. (2007). Nutritional manipulation of the fatty acid composition of sheep meat: a review. Journal of Agricultural Science, 145, 419-434.

Sinclair, L.A., Cooper, S.L., Chikunya, S., Wilkinson, R.G., Hallett, K.G., Enser, M. \& Wood, J.D. (2005). Biohydrogenation of n-3 polyunsaturated fatty acids in the rumen and their effects on microbial metabolism and plasma fatty acid concentrations in sheep. Animal Science, 81, 239-248.

Stokes, R.S., Van Emon, M.L., Loy, D.D and Hansen, S.L. (2015). Assessment of algae meal as a ruminat feedstuff: Nutrient digestibility in sheep as a model species. Journal of Animal Science 93, 5386-5394.

Van Soest, P,J., Robertson, J.B. \& Lewis, B.A. (1991). Methods for dietary fibre, neutral detergent fibre and non-starch polysaccharides in relation to animal nutrition. Journal of Dairy Science, 74, 3583-3597.

Vatansever, L., Kurt, E., Enser, M., Nute, G.R., Scollan, N.D., Wood, J.D. \& Richardson, R.I. (2000). Shelf life and eating quality of beef from cattle of different breeds given 
diets differing in their n-3 polyunsaturated fatty acid composition. Animal Science, 71, 471-482.

Wachira, A.M., Sinclair, L.A., Wilkinson, R.G., Enser, M., Wood, J.D. \& Fisher, A.V. (2002). Effects of dietary fat source and breed on the carcass composition, n-3 polyunsaturated fatty acid and conjugated linoleic acid content of sheep meat and adipose tissue. British Journal of Nutrition, 88, 697-709.

Welch, A.A., Lund, E., Amiano, P., Dorronsoro, M., Brustad, M., Kumle, M., Rodriguez, M., Lasheras, C., Janzon, L., Jansson, J., Luben, R., Spencer, E.A,, Overvad, K., Tjønneland, A., Clavel-Chapelon, F., Linseisen, J., Klipstein-Grobusch, K., Benetou, V., Zavitsanos, X., Tumino, R., Galasso, R., Bueno-De-Mesquita, H.B., Ocké, M.C., Charrondière, U,R. \& Slimani, N. (2002). Variability of fish consumption within the 10 European countries participating in the European Investigation into Cancer and Nutrition (EPIC) study. Public Health Nutrition, 5, 1273-1285.

Wood, J.D., Enser, M., Fisher, A.V., Nute, G.R., Sheard, P.R., Richardson, R.I. \& Whittington, F.M. (2008). Fat deposition, fatty acid composition and meat quality: A review. Meat Science, 78, 343-358.

Zárate, R., el Jabber-Vazdekis, N. \& Ramírez-Moreno, R. (2016). Importance of polyunsaturated fatty acids from marine algae. In: Omega-3 fatty acids: keys to nutritional health (edited by M.V. Hegde., A.A. Zanwar. \& S.P. Adekar). Pp 101-126. Springer International Publishing AG, Switzeland.

Zárate, R., el Jabber-Vazdekis, N., Tejera, N., Pérez, J.A. \& Rodríguez, C. (2017). Significance of long chain polyunsaturated fatty acids in human health. Clinical and Translational Medicine 6: 25. 
Table 1 Fatty acid composition (\% of total fatty acids), and total fatty acid content (mg/100 g of fresh tissue) of the longissimus thoracis muscle of beef heifers fed a concentrate based diet that contained no microalgae (Control), a low inclusion of microalgae (LMA) or a high inclusion of microalgae (HMA)

\begin{tabular}{|c|c|c|c|c|c|}
\hline Fatty acid & Control & LMA & HMA & s.e.d. & $P$-value \\
\hline C14:0 & 2.12 & 2.15 & 2.30 & 0.155 & 0.497 \\
\hline C16:0 & $22.97^{b}$ & $24.24^{\mathrm{ab}}$ & $25.05^{a}$ & 0.630 & 0.013 \\
\hline C16:1n-7 & $3.35^{a}$ & $3.24^{\mathrm{ab}}$ & $2.96^{\mathrm{b}}$ & 0.155 & 0.053 \\
\hline C18:0 & $12.25^{\mathrm{ab}}$ & $11.61^{\mathrm{b}}$ & $12.54^{a}$ & 0.322 & 0.029 \\
\hline C18:1trans-11 & $1.99^{a}$ & $1.91^{\mathrm{ab}}$ & $1.79^{b}$ & 0.069 & 0.031 \\
\hline C18:1n-9 & $36.45^{\mathrm{a}}$ & $35.40^{a}$ & $33.24^{b}$ & 0.677 & $<0.001$ \\
\hline C18:1trans-9 & $0.45^{\mathrm{b}}$ & $0.91^{\mathrm{a}}$ & $1.15^{\mathrm{a}}$ & 0.151 & $<0.001$ \\
\hline C18:2n-6 & 2.99 & 2.66 & 2.60 & 0.273 & 0.319 \\
\hline C18:2cis-9, trans-11 & 0.30 & 0.24 & 0.23 & 0.031 & 0.081 \\
\hline C18:2trans-10,cis-12 & 0.03 & 0.03 & 0.03 & 0.003 & 0.669 \\
\hline C18:3n-3 & 0.15 & 0.14 & 0.12 & 0.010 & 0.083 \\
\hline$C 20: 3 n-6$ & $0.27^{a}$ & $0.19^{b}$ & $0.20^{\mathrm{b}}$ & 0.027 & 0.014 \\
\hline$C 20: 4 n-6$ & 1.16 & 0.95 & 1.04 & 0.095 & 0.103 \\
\hline$C 20: 5 n-3$ & $0.50^{c}$ & $0.92^{b}$ & $1.20^{\mathrm{a}}$ & 0.080 & $<0.001$ \\
\hline$C 22: 4 n-6$ & $1.25^{\mathrm{a}}$ & $1.17^{\mathrm{a}}$ & $1.07^{b}$ & 0.038 & 0.001 \\
\hline$C 22: 5 n-3$ & $0.77^{\mathrm{a}}$ & $0.53^{b}$ & $0.49^{b}$ & 0.068 & 0.001 \\
\hline$C 22: 6 n-3$ & $0.31^{c}$ & $0.89^{b}$ & $1.05^{\mathrm{a}}$ & 0.053 & $<0.001$ \\
\hline$\Sigma \mathrm{n}-6$ fatty acids ${ }^{1}$ & 5.68 & 4.96 & 4.92 & 0.388 & 0.117 \\
\hline$\Sigma \mathrm{n}-3$ fatty acids $^{2}$ & $1.73^{b}$ & $2.47^{\mathrm{a}}$ & $2.86^{\mathrm{a}}$ & 0.154 & $<0.001$ \\
\hline Total FA, mg/100g fresh tissue & 3359 & 3683 & 3241 & 302.9 & 0.341 \\
\hline
\end{tabular}

${ }^{1} \Sigma \mathrm{n}-6$ fatty acids $=\mathrm{C} 18: 2 \mathrm{n}-6+\mathrm{C} 20: 3 \mathrm{n}-6+\mathrm{C} 20: 4 \mathrm{n}-6+\mathrm{C} 22: 4 \mathrm{n}-6$.

${ }^{2} \Sigma \mathrm{n}-3$ fatty acids $=\mathrm{C} 18: 3 n-3+\mathrm{C} 20: 5 \mathrm{n}-3+\mathrm{C} 22: 5 n-3+\mathrm{C} 22: 6 n-3$.

${ }^{a, b, c}$ Means in a row with different superscripts letters differ $(P<0.05)$. 
Table 2 Fatty acid classes (mg/100 $\mathrm{g}$ of fresh tissue) and ratios of the longissimus thoracis muscle of beef heifers fed a concentrate based diet that contained no microalgae (Control), a low inclusion of microalgae (LMA) or a high inclusion of microalgae (HMA)

\begin{tabular}{lccccc}
\hline Item & Control & LMA & HMA & s.e.d. & $P$-value \\
\hline SFA $^{1}$ & 1270 & 1399 & 1295 & 129.2 & 0.580 \\
MUFA $^{2}$ & 1464 & 1575 & 1307 & 136.7 & 0.172 \\
PUFA $^{3}$ & 242 & 272 & 254 & 11.7 & 0.063 \\
P:S ratio & 0.21 & 0.20 & 0.20 & 0.017 & 0.898 \\
n-6:n-3 ratio $^{5}$ & $2.88^{\text {a }}$ & $1.91^{\text {b }}$ & $1.61^{\text {c }}$ & 0.082 & $<0.001$ \\
\hline
\end{tabular}

\footnotetext{
${ }^{1}$ Saturated fatty acids.

${ }^{2}$ Monounsaturated fatty acids.

${ }^{3}$ Polyunsaturated fatty acids.

${ }^{4} \mathrm{P}: \mathrm{S}=$ total polyunsaturated to total saturated fatty acids ratio.

${ }^{5} \mathrm{n}-6: \mathrm{n}-3=$ total $\mathrm{n}-6(\mathrm{C} 18: 2 \mathrm{n}-6+\mathrm{C} 20: 3 \mathrm{n}-6+\mathrm{C} 20: 4 \mathrm{n}-6+\mathrm{C} 22: 4 \mathrm{n}-6)$ to $\mathrm{n}-3$ fatty acids (C18:3n$3+\mathrm{C} 20: 5 n-3+\mathrm{C} 22: 5 n-3+\mathrm{C} 22: 6 n-3)$.

a,b,c Means in a row with different superscripts letters differ $(P<0.05)$.
} 
Table 3 Fatty acid composition (\% of total fatty acids) and fatty acid content (mg/100 g of tissue) of the subcutaneous adipose tissue of beef heifers fed a concentrate based diet that contained no microalgae (Control), a low inclusion of microalgae (LMA) or a high inclusion of microalgae (HMA)

\begin{tabular}{|c|c|c|c|c|c|}
\hline Fatty acid & Control & LMA & HMA & s.e.d. & $P$-value \\
\hline C14:0 & $2.93^{b}$ & $3.07^{\mathrm{ab}}$ & $3.55^{a}$ & 0.211 & 0.022 \\
\hline C16:0 & $25.40^{c}$ & $27.38^{b}$ & $29.43^{a}$ & 0.612 & $<0.001$ \\
\hline C16:1n-7 & 4.18 & 4.18 & 4.05 & 0.389 & 0.932 \\
\hline C18:0 & 11.38 & 11.34 & 11.74 & 0.677 & 0.816 \\
\hline C18:1 trans-11 & $1.82^{\mathrm{a}}$ & $1.73^{\mathrm{a}}$ & $1.56^{\mathrm{b}}$ & 0.067 & 0.003 \\
\hline C18:1n-9 & $38.20^{\mathrm{a}}$ & $35.46^{b}$ & $31.81^{\mathrm{c}}$ & 0.847 & $<0.001$ \\
\hline C18:1 trans-9 & $0.70^{c}$ & $1.78^{\mathrm{b}}$ & $3.10^{\mathrm{a}}$ & 0.398 & $<0.001$ \\
\hline C18:2n-6 & $1.04^{a}$ & $0.92^{\mathrm{ab}}$ & $0.85^{\mathrm{b}}$ & 0.066 & 0.026 \\
\hline C18:2 cis-9, trans-11 & $0.24^{a}$ & $0.19^{\mathrm{ab}}$ & $0.16^{b}$ & 0.024 & 0.013 \\
\hline C18:2 trans-10, cis-12 & $0.02^{b}$ & $0.04^{\mathrm{a}}$ & $0.05^{a}$ & 0.008 & 0.005 \\
\hline C18:3n-3 & 0.11 & 0.09 & 0.09 & 0.007 & 0.057 \\
\hline$C 20: 3 n-6$ & $0.04^{a}$ & $0.03^{b}$ & $0.03^{b}$ & 0.005 & 0.017 \\
\hline$C 20: 4 n-6$ & 0.04 & 0.03 & 0.04 & 0.005 & 0.077 \\
\hline$C 20: 5 n-3$ & 0.09 & 0.06 & 0.07 & 0.013 & 0.148 \\
\hline$C 22: 4 n-6$ & 1.27 & 1.23 & 1.22 & 0.041 & 0.326 \\
\hline$C 22: 5 n-3$ & $0.04^{b}$ & $0.06^{a}$ & $0.06^{a}$ & 0.007 & 0.023 \\
\hline$C 22: 6 n-3$ & 0.14 & 0.10 & 0.13 & 0.021 & 0.350 \\
\hline$\Sigma \mathrm{n}-6$ fatty acids ${ }^{1}$ & $2.40^{a}$ & $2.21^{\mathrm{ab}}$ & $2.14^{\mathrm{b}}$ & 0.075 & 0.008 \\
\hline$\Sigma \mathrm{n}-3$ fatty acids ${ }^{2}$ & 0.37 & 0.32 & 0.34 & 0.034 & 0.323 \\
\hline $\begin{array}{l}\text { Total fatty acids }(\mathrm{mg} / 100 \mathrm{~g} \text { of } \\
\text { tissue) }\end{array}$ & 82221 & 79438 & 77601 & 2121.8 & 0.119 \\
\hline
\end{tabular}

${ }^{1} \Sigma \mathrm{n}-6$ fatty acids $=\mathrm{C} 18: 2 \mathrm{n}-6+\mathrm{C} 20: 3 \mathrm{n}-6+\mathrm{C} 20: 4 \mathrm{n}-6+\mathrm{C} 22: 4 \mathrm{n}-6$, ${ }^{2} \Sigma \mathrm{n}-3$ fatty acids $=\mathrm{C} 18: 3 \mathrm{n}-3+\mathrm{C} 20: 5 \mathrm{n}-3+\mathrm{C} 22: 5 \mathrm{n}-3+\mathrm{C} 22: 6 \mathrm{n}-3$. $\mathrm{a}, \mathrm{b}, \mathrm{c}$ Means in a row with different superscripts letters differ, $(P<0.05)$. 
Table 4 Sensory attributes shear force and toughness of cooked steaks from beef heifers fed a concentrate based diet that contained no microalgae (Control), a low inclusion of microalgae (LMA) or a high inclusion of microalgae (HMA)

\begin{tabular}{|c|c|c|c|c|c|}
\hline Attribute & Control & LMA & HMA & s.e.d. & $P$-value \\
\hline \multicolumn{6}{|l|}{ Odours $^{1}$} \\
\hline Dairy & 2.9 & 2.6 & 2.9 & 0.34 & 0.664 \\
\hline Beefy & 6.3 & 5.9 & 5.9 & 0.33 & 0.309 \\
\hline Roast & 4.8 & 4.4 & 4.5 & 0.37 & 0.519 \\
\hline \multicolumn{6}{|l|}{ Flavours $^{1}$} \\
\hline Beefy & 7.4 & 7.1 & 6.9 & 0.29 & 0.258 \\
\hline Roast & 5.7 & 5.1 & 5.2 & 0.38 & 0.216 \\
\hline Sweet & 2.6 & 2.4 & 2.4 & 0.28 & 0.812 \\
\hline Salty & 1.8 & 1.9 & 1.9 & 0.23 & 0.877 \\
\hline Livery & 2.4 & 2.6 & 2.8 & 0.22 & 0.214 \\
\hline Seaweedy & $0.7^{\mathrm{c}}$ & $1.3^{b}$ & $1.8^{a}$ & 0.21 & $<0.001$ \\
\hline Overall richness of flavour & 7.2 & 6.9 & 7.1 & 0.27 & 0.539 \\
\hline \multicolumn{6}{|l|}{ Aftertastes $^{1}$} \\
\hline Metallic & 3.4 & 3.4 & 3.3 & 0.34 & 0.972 \\
\hline Umami & 5.4 & 5.2 & 5.0 & 0.39 & 0.475 \\
\hline Fat coating & 2.7 & 2.9 & 2.7 & 0.29 & 0.694 \\
\hline Livery & 2.4 & 2.5 & 2.6 & 0.24 & 0.728 \\
\hline Unusual & 0.9 & 1.1 & 1.3 & 0.23 & 0.138 \\
\hline \multicolumn{6}{|l|}{ Texture } \\
\hline Tenderness $^{2}$ & $6.6^{\mathrm{ab}}$ & $6.0^{\mathrm{b}}$ & $7.2^{\mathrm{a}}$ & 0.31 & $<0.001$ \\
\hline Juiciness $^{3}$ & 6.5 & 6.0 & 6.3 & 0.33 & 0.363 \\
\hline Fat mouth feel ${ }^{1}$ & 2.5 & 2.4 & 2.4 & 0.28 & 0.879 \\
\hline Shear force $(N)$ & $40.7^{b}$ & $46.3^{a}$ & $35.2^{c}$ & 2.13 & $<0.001$ \\
\hline Toughness (N.s) & $129.9^{a b}$ & $140.5^{\mathrm{a}}$ & $111.1^{\mathrm{b}}$ & 8.52 & 0.010 \\
\hline
\end{tabular}

${ }^{1}$ scale 1-15; $0=$ weak, $15=$ strong

${ }^{2}$ scale $1-15 ; 0=$ hard to chew, $15=$ melt in the mouth

${ }^{3}$ scale 1-15; $0=$ dry, $15=$ juicy

a,b,c Means in a row with different superscripts letters differ, $(P<0.05)$. 
Table 5 Carcase characteristics and performance of beef heifers fed a concentrate based diet that contained no microalgae (Control), low inclusion of microalgae (LMA) or a high inclusion of microalgae (HMA)

\begin{tabular}{lccccc}
\hline Item & Control & LMA & HMA & s.e.d. & Significance \\
\hline Initial live weight $(\mathrm{kg})$ & 509 & 509 & 509 & 6.87 & 1.000 \\
Slaughter weight $(\mathrm{kg})$ & 659 & 661 & 660 & 10.16 & 0.970 \\
DLWG $^{1}(\mathrm{~kg} / \mathrm{d})$ & 1.57 & 1.59 & 1.58 & 0.087 & 0.968 \\
Carcase weight $(\mathrm{kg})^{\text {Carcase conformation }}{ }^{2}$ & 349 & 351 & 351 & 8.48 & 0.968 \\
Carcase fat class $^{3}$ & 8.0 & 8.4 & 8.0 & 0.41 & 0.537 \\
\hline
\end{tabular}

${ }^{1}$ Daily live weight gain.

${ }^{2}$ Conformation, $1=$ poor to $15=$ excellent.

${ }^{3}$ Fat Class, $1=$ lean to $15=$ fat. 
Table S1 Fatty acid and chemical composition of diets fed to beef heifers that contained no microalgae (Control), a low inclusion of microalgae (LMA) or a high inclusion of microalgae (HMA)

\begin{tabular}{lccc}
\hline & Control & LMA & HMA \\
\hline Fatty acid composition (g/kg DM) & & & \\
C14:0 & 0.17 & 0.62 & 1.01 \\
C16:0 & 2.89 & 7.66 & 12.08 \\
C18:0 & 0.23 & 0.33 & 0.43 \\
C18:1n-9 & 1.70 & 1.69 & 1.65 \\
C18:2n-6 & 7.33 & 7.14 & 7.05 \\
C18:3n-3 & 0.84 & 0.84 & 0.81 \\
C20:5n-3 & $\mathrm{ND}^{2}$ & 0.03 & 0.05 \\
C22:5n-3 & $\mathrm{ND}^{2}$ & 0.48 & 0.95 \\
C22:6n-3 & $\mathrm{ND}^{2}$ & 2.04 & 4.08 \\
Total FA content & 13.3 & 21.2 & 29.2 \\
Chemical composition (g/kg DM) & & & \\
Dry matter (g/kg) & 873 & 867 & 870 \\
Organic matter & 965 & 959 & 953 \\
Crude protein $(\mathrm{N}$ x 6.25) & 139 & 126 & 126 \\
Neutral detergent fibre & 259 & 241 & 244 \\
\hline Not detected & & &
\end{tabular}

${ }^{1}$ Not detected 
Table S2 Correlation coefficients ( $P$-value) between "seaweedy flavour" in steaks and the proportion of n-3 PUFA in the muscle from beef heifers fed diets varying in their inclusion of microalgae

\begin{tabular}{lcccc}
\hline & $\begin{array}{c}\text { C18:3n-3 } \\
\alpha-l i n o l e n i c\end{array}$ & $\begin{array}{c}\text { C20:5n-3 } \\
\text { EPA }^{1}\end{array}$ & $\begin{array}{c}\text { C22:5n-3 } \\
\text { DPA }^{2}\end{array}$ & $\begin{array}{c}\text { C22:6n-3 } \\
\text { DHA }^{3}\end{array}$ \\
\hline $\begin{array}{l}\text { Seaweedy } \\
\text { flavour }\end{array}$ & $-0.43(0.019)$ & $0.48(0.007)$ & $-0.38(0.037)$ & $0.60(0.000)$ \\
\hline
\end{tabular}

